\title{
Níveis Nutricionais de Cálcio e de Fósforo Disponível para Aves de Reposição Leves e Semipesadas de 7 a 12 Semanas de Idade ${ }^{1}$
}

\section{José Geraldo de Vargas Junior ${ }^{2}$, Luiz Fernando Teixeira Albino ${ }^{3}$, Horacio Santiago Rostagno ${ }^{3}$, Paulo Cezar Gomes ${ }^{3}$, Edwiney Sebastião Cupertino ${ }^{4}$, Débora Cristine de Oliveira Carvalho ${ }^{4}$, Marcelo Aparecido da Silva ${ }^{5}$, Rogério Pinto ${ }^{2}$}

\begin{abstract}
RESUMO - Foram realizados quatro experimentos, dois com aves leves e dois com aves semipesadas, em duas diferentes fases crescimento (7 a 12 semanas de idade) e produção de ovos (20 a 28 semanas de idade) - , com o objetivo de determinar as exigências e os efeitos dos níveis de cálcio e de fósforo disponível na produção. Durante a fase de 13 a 19 semanas, as aves foram identificadas por tratamento e submetidas à ração comercial única. Utilizou-se para cada experimento um delineamento inteiramente ao acaso, com cinco níveis de cálcio $(0,60 ; 0,70 ; 0,80 ; 0,90$ e 1,00\%) ou cinco níveis de fósforo disponível $(0,25 ; 0,30 ; 0,35 ; 0,40$ e $0,45 \%)$, quatro repetições e 16 aves/ UE para a fase de crescimento e 8 aves/ UE para a fase de produção. As características avaliadas para a fase de crescimento foram ganho de peso, consumo de ração, conversão alimentar, resistência óssea, cinza e cálcio (experimentos de cálcio) ou fósforo ósseo (experimentos de fósforo disponível), enquanto para a fase de produção de ovos foram avaliados consumo de ração, produção de ovos, peso médio dos ovos, massa de ovo e conversão alimentar (g de ração/g de ovo e kg de ração/dúzia de ovo). Foram estimadas exigências de cálcio de $0,834 \%$ ou $406 \mathrm{mg}$ / ave/ dia para aves leves e de $0,815 \%$ ou $440 \mathrm{mg}$ /ave/dia para aves semipesadas e para fósforo disponível, de $0,411 \%$ ou $200 \mathrm{mg} /$ ave/dia para aves leves e de $0,361 \%$ ou $184 \mathrm{mg} /$ ave/dia para aves semipesadas.
\end{abstract}

Palavras-chave: aves de reposição leves, aves de reposição semipesadas, cálcio, fósforo disponível, exigência nutricional

\section{Nutritional Levels of Calcium and Available Phosphorus for White-Egg Pullets and Brown-Egg Pullets from 7 to 12 Weeks of Age}

\begin{abstract}
Four experiments were carried out using white-egg pullets and brown-egg pullets in two different phases, growth phase ( 7 to 12 age weeks) and production phase (20 to 28 age weeks), with objective to determine requirements of calcium and available phosphorus and the effects of levels calcium e available phosphorus in production. Chickens from 13 to 19 weeks age were identified for treatment and fed only commercial diet. For each experiment, the chickens were allotted in a completely randomized design with five calcium levels $(0.60,0.70,0.80,0.90$, and $1.00 \%)$ or five level available phosphorus $(0.25,0.30$, $0.35,0.40$, and $0.45 \%$ ), four replicates and 16 pullets/EU for the growth phase and 8 chickens/EU for the production phase. The characteristics evaluated for the growth phase were weight gain, feed intake, feed: gain ratio, bone resistance, ash and bone calcium (calcium experiments) or bone phosphorus (experiments phosphorus), while for the egg production phase were evaluated ration consumption, eggs production, egg weight, egg mass and feed conversion (g ration/g egg and kg of ration/dozen of egg). Calcium requirements of $0.834 \%$ or $406 \mathrm{mg} /$ pullets/day for white egg pullets and $0.815 \%$ or $440 \mathrm{mg} /$ pullets/day for brown eggs pullets were estimated and for available phosphorus, requirements of $0.411 \%$ or $200 \mathrm{mg} / \mathrm{pullets} / \mathrm{day}$ for white egg pullets and $0.361 \%$ or $184 \mathrm{mg} /$ pullets/day for brown eggs pullets were estimated.
\end{abstract}

Key Words: white-egg pullets, brown-egg pullets, calcium available phosphorus, nutritional requirements

\section{Introdução}

Cálcio e fósforo são os principais minerais no desenvolvimento das aves, pois estão associados principalmente ao metabolismo e à formação óssea. A utilização destes minerais pelo organismo depende da idade e do tipo de animal, uma vez que as recomenda- ções nutricionais variam entre as fases de crescimento e de produção. Shafey et al. (1990) citam que existem diferenças genéticas quanto ao requerimento de cálcio para os vários tipos de aves imaturas.

A fase de crescimento das aves baseia-se no grau de alterações fisiológicas determinantes na formação da estrutura corporal, relacionadas à formação óssea

\footnotetext{
1 Parte da tese de Doutorado apresentado pelo primeiro autor à UFV.

2 Professor do DZO/CCA/UFES, Alegre - ES. E.mail: jgvargas@pop.com.br

3 Professor do DZO/ UFV, Campus Universitário - Viçosa MG, Brasil CEP: 36571-000

4 Estudante de Doutorado em Zootecnia, DZO/UFV, Viçosa MG, Brasil.

5 Zootecnista, DSc em Nutrição de Monogástricos, Agroceres Nutrição Animal, Rio Claro, SP.
} 
e muscular, empenamento e desenvolvimento sexual; logo, espera-se que qualquer mudança em uma dessas fases possa alterar seu desempenho durante a produção de ovos. Assim, um bom programa de alimentação na fase de crescimento é essencial ao desempenho das aves na fase de produção de ovos.

Aves alimentadas combaixo nível de cálcio na dieta apresentam menor taxa de crescimento quando comparadas àquelas recebendo níveis normais. Entretanto, o nível de cálcio durante o período de crescimento não tem influência na maturidade sexual medida ao primeiro ovo, mas influencia a produção de ovos, a mortalidade, o consumo e a eficiência alimentar durante a fase de produção (Hamilton \& Cipera, 1981). Portanto, o consumo de ração provavelmente tem maior impacto na qualidade do ovo formado inicialmente que na redução de seu número (Moran Jr., 1986).

Keshavarz (1987), estudando níveis de cálcio com baixo teor de fósforo disponível, observaram alta mortalidade decorrente de lesões renais durante o período de crescimento e, quando as aves não morriam, tinham sua produção afetada.

Hamilton \& Cipera (1981) observaram que as aves têm capacidade de adaptação a dietas contendo baixo nível de cálcio por aumento na capacidade de absorção intestinal. Em adição, aves jovens têm melhor capacidade de absorver cálcio que as aves velhas. Leeson et al. (1986) observaram que poedeiras imaturas absorvem menos cálcio que poedeiras em produção, sugerindo que certas aves podem ter desvantagens com dieta de baixo teor de cálcio, em função da idade. Keshavarz \& Nakajima (1993) não observaram em poedeiras redução da capacidade de absorver ou reter cálcio ou utilizar cálcio do osso para formação da casca do ovo.

Objetivou-se estabelecer as exigências nutricionais de cálcio e de fósforo disponível para aves de reposição leves e semipesadas de 7 a 12 semanas de idade e os efeitos desses minerais na fase de recria sobre a produção de ovos.

\section{Material e Métodos}

Os experimentos foram realizados no Setor de Avicultura e no Laboratório de Nutrição Animal do Departamento de Zootecnia da Universidade Federal de Viçosa, no período de janeiro a setembro de 1999. Foram utilizadas 1280 aves de reposição, sendo 640 aves leves (Hy Line W36) e 640 semipesadas (Hy Line Brown).

\footnotetext{
R. Bras. Zootec., v.33, n.4, p.936-946, 2004
}

As aves foram distribuídas em quatro experimentos - dois para determinação das exigências de cálcio e dois para determinação das exigências de fósforo disponível, respectivamente, com aves leves e semipesadas.

Foram utilizadas duas fases de vida. Na fase de recria, as aves foram alojadas em galpão de alvenaria subdivididos em boxes de 1,00 x 2,10 m e, na fase de produção de ovos, foram alojadas em galpão de gaiola. O período experimental da fase de crescimento foi de 7 a 12 semanas de idade e da fase de produção, de 20 a 28 semanas de idade.

Até a sexta semana, as aves foram criadas em galpão convencional, sendo transferidas para galpão experimental após esse período. Após o término do período experimental (12 semanas de idade), foram identificadas de acordo com o tratamento recebido e recriadas em galpão de gaiolas até o início da postura, onde foram distribuídas dentro do peso médio do tratamento, para verificar os possíveis efeitos dos níveis de cálcio na fase de recria sobre os parâmetros produtivos na fase de produção de ovos. As aves, durante a fase de 13 a 19 semanas, foram alimentadas com ração comercial à base de milho e farelo de soja, contendo15\% de proteína bruta, $2900 \mathrm{kcal}$ de EM/kg de ração, 0,820\% de cálcio e 0,386\% de fósforo disponível (NRC, 1994; Rostagno et al., 1994).

No período experimental (7 a 12 semanas), as aves receberam rações formuladas à base de milho e farelo de soja, de forma a atender às recomendações nutricionais descritas por Rostagno et al. (1994) e NRC (1994), exceto para cálcio, para os experimentos de cálcio, e fósforo disponível, para os experimentos de fósforo. Nos experimentos de cálcio, a ração basal foi suplementada com calcário em substituição ao material inerte, obtendo-se cinco níveis $(0,60$; 0,70; 0,80; 0,90 e 1,00\%) de cálcio na ração (Tabela 1). Para os experimentos de fósforo disponível, a ração basal foi suplementada com fosfato bicálcico e calcário, em substituição ao material inerte, obtendo-se cinco níveis $(0,25 ; 0,30 ; 0,35 ; 0,40$ e $0,45 \%)$ de fósforo disponível na ração. A ração utilizada na fase de produção de ovos seguiu as recomendações nutricionais dos autores supracitados.

As características avaliadas na fase de crescimento foram ganho de peso (g/ave/dia), consumo de ração (g/ave/dia), conversão alimentar, resistência óssea a quebra $(\mathrm{kgf} / \mathrm{mm})$, cinza óssea (\%) e cálcio ósseo (\%) ou fósforo ósseo (\%). Ao término do período experimental, foram abatidas duas aves por 
Tabela 1 - Composição percentual e valores nutricionais calculados das rações experimentais para os experimentos de cálcio (ração 1) e de fósforo disponível (ração 2) para a fase de crescimento e para a fase de produção (ração 3)

Table 1 - Percentage composition and calculated nutritional values of the experimental rations for calcium experiments (ration 1) and for available phosphorus (ration 2) for growth phase and for production phase (ration 3)

\begin{tabular}{|c|c|c|c|}
\hline $\begin{array}{l}\text { Ingrediente } \\
\text { Ingredients }\end{array}$ & $\begin{array}{l}\text { Ração } 1 \\
\text { Ration } 1\end{array}$ & $\begin{array}{l}\text { Ração } 2 \\
\text { Ration } 2\end{array}$ & $\begin{array}{l}\text { Ração } 3 \\
\text { Ration } 3\end{array}$ \\
\hline Milho & 70,345 & 70,345 & 62,449 \\
\hline $\begin{array}{l}\text { Corn } \\
\text { Farelo de soja } \\
\text { Soybean meal }\end{array}$ & 21,595 & 21,595 & 23,013 \\
\hline $\begin{array}{l}\text { Calcário } \\
\text { Limestone }\end{array}$ & 0,516 & 1,374 & 8,400 \\
\hline $\begin{array}{l}\text { Fosfato bicálcico } \\
\text { Dicalcium phosphate }\end{array}$ & 1,340 & 0,799 & 1,256 \\
\hline $\begin{array}{l}\text { DL-Metionina } \\
\text { DL-Methionine }\end{array}$ & 0,080 & 0,080 & 0,146 \\
\hline $\begin{array}{l}\text { Sal } \\
\text { Salt }\end{array}$ & 0,278 & 0,278 & 0,367 \\
\hline $\begin{array}{l}\text { Cloreto de colina } 60 \% \\
\text { Choline cloret }\end{array}$ & 0,040 & 0,040 & 0,020 \\
\hline $\begin{array}{l}\text { Suplemento vitamínico } \\
\text { Vitamin supplement }\end{array}$ & 0,100 & 0,100 & 0,100 \\
\hline $\begin{array}{l}\text { Suplemento mineral } \\
\text { Mineral supplement }\end{array}$ & 0,050 & 0,050 & 0,050 \\
\hline $\begin{array}{l}\text { Virginamicina } \\
\text { Virginamicin }\end{array}$ & 0,050 & 0,050 & - \\
\hline $\begin{array}{l}\text { Anticoccidiano } 4 \\
\text { Anticoccidiostatic }\end{array}$ & 0,035 & 0,035 & - \\
\hline $\begin{array}{l}\text { Antioxidante } \\
\text { Antioxidant }\end{array}$ & 0,010 & 0,010 & 0,010 \\
\hline $\begin{array}{l}\text { Inerte } \\
\text { Inert }\end{array}$ & 5,562 & 5,244 & 2,663 \\
\hline \multicolumn{4}{|c|}{$\begin{array}{l}\text { Composição calculada } \\
\text { Calculated composition }\end{array}$} \\
\hline $\begin{array}{l}\text { Energia metabolizável (kcal/kg) } \\
\text { Metabolizable energy }\end{array}$ & 2900 & 2900 & 2800 \\
\hline $\begin{array}{l}\text { Proteína bruta (\%) } \\
\text { Crude protein }\end{array}$ & 16,00 & 16,00 & 16,00 \\
\hline $\begin{array}{l}\text { Metionina (\%) } \\
\text { Methionine }\end{array}$ & 0,339 & 0,339 & 0,400 \\
\hline $\begin{array}{l}\text { Metionina + Cistina (\%) } \\
\text { Methionine + Cystine }\end{array}$ & 0,615 & 0,615 & 0,671 \\
\hline $\begin{array}{l}\text { Lisina (\%) } \\
\text { Lysine }\end{array}$ & 0,789 & 0,789 & 0,810 \\
\hline $\begin{array}{l}\text { Treonina (\%) } \\
\text { Threonine }\end{array}$ & 0,574 & 0,574 & 0,578 \\
\hline $\begin{array}{l}\text { Triptofano (\%) } \\
\text { Thryptphan }\end{array}$ & 0,201 & 0,201 & 0,204 \\
\hline $\begin{array}{l}\text { Cálcio (\%) } \\
\text { Calcium }\end{array}$ & 0,600 & 0,800 & 3,580 \\
\hline $\begin{array}{l}\text { Fósforo total } \\
\text { Total phosphorus }\end{array}$ & 0,549 & 0,454 & 0,520 \\
\hline $\begin{array}{l}\text { Fósforo disponível (\%) } \\
\text { Available phophorus }\end{array}$ & 0,350 & 0,250 & 0,330 \\
\hline $\begin{array}{l}\text { Sódio (\%) } \\
\text { Sodium }\end{array}$ & 0,145 & 0,145 & 0,180 \\
\hline \multicolumn{4}{|c|}{ 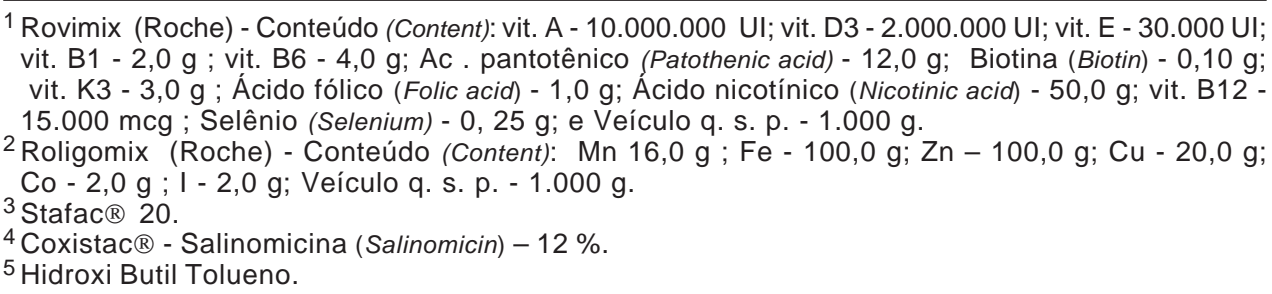 } \\
\hline
\end{tabular}


unidade experimental, por meio de deslocamento cervical, para retirada da tíbia e posterior análises dos parâmetros ósseos. Na fase de produção de ovos, o período experimental durou oito semanas e foi subdividido em dois períodos de quatro semanas, em que se avaliaram o consumo de ração (g/ave/dia), a produção de ovos (\%), o peso médio dos ovos (g), a massa de ovo (g de ovo/ave/dia) e a conversão alimentar (g de ração/ g de ovo e kg de ração/ dúzia de ovo).

Para obtenção do peso médio dos ovos e massa de ovo, os ovos dos últimos quatros dias de cada período experimental foram coletados em separado, de acordo com a unidade experimental e pesados diariamente, sendo o peso médio desses ovos considerado a média do período experimental.

As análises para determinação dos teores de cinzas, de cálcio e de fósforo nos ossos (tíbias) foram realizadas de acordo com a metodologia descrita por Silva (1990), e os parâmetros de resistência óssea foram determinados no osso in natura, em prensa INSTRON- modelo 4204, pertencente ao Laboratório de Papel e Celulose do Departamento de Engenharia Florestal da Universidade Federal de Viçosa. Após as análises de resistência óssea, os ossos foram desengordurados em extrator tipo "Soxlet" e colocados em estufa a $55^{\circ} \mathrm{C}$, durante uma hora, sendo triturados logo após para análises de cálcio e fósforo.

Em todos os experimentos, as aves foram distribuídas em delineamento inteiramente ao acaso, em cinco tratamentos, quatro repetições e 16 aves por unidade experimental, para a fase de recria, e oito aves por unidade experimental, para a fase de produção de ovos. As aves, na fase de recria, foram classificadas conforme o peso médio (380 e 450g, respectivamente, para aves leves e semipesadas).

As análises estatísticas dos resultados foram feitas utilizando o programa SAEG - Sistema para Análises Estatísticas e Genéticas (UFV, 1997). Foi feita análise de variância com posterior uso de regressão polinomial, para cada variável estudada, além do teste de F na comparação de médias dos tratamentos entre aves leves e semipesadas. O modelo estatístico empregado foi:

$$
Y_{i j k}=\mu+N_{i}+P_{j}+N_{i} / P j+E_{i j k}
$$

em que: $\quad Y_{i j k}=$ parâmetro observado na unidade experimental k, do nível de cálcio ou fósforo disponível $\mathrm{i}$, dentro do tipo de ave $\mathrm{j} ; \mu=$ média geral observada; $\mathrm{N}_{\mathrm{i}}=$ efeito do nível de nutriente (cálcio ou fósforo disponível) $\mathrm{i}, \mathrm{i}=1$, 2, 3, 4 e 5; $\mathrm{P}_{\mathrm{j}}=$ efeito do tipo de ave de reposição $\mathrm{j}$, $\mathrm{j}=$ leve ou semipesada; $\mathrm{N}_{\mathrm{i}} /$ $\mathrm{P}_{\mathrm{j}}=$ efeito do nível de nutriente $\mathrm{i}$, dentro do tipo de ave $\mathrm{j} ; \mathrm{E}_{\mathrm{ijk}}=$ erro aleatório associado a cada observação.

\section{Resultados e Discussão}

\section{Exigências nutricionais de cálcio}

\section{Fase de crescimento}

Observou-se que os diferentes níveis de cálcio não influenciaram o consumo de ração, a resistência óssea, o teor de cinza e o teor de cálcio ósseo (Tabela 2). Entretanto, na média dos tratamentos as aves semipesadas tiveram maiores valores para consumo de ração, ganho de peso, resistência óssea, além de melhor conversão alimentar e menor teor de cinza óssea que as aves leves.

Para ganho de peso, verificou-se maximização do ganho (12,43 g) no nível de 0,799\% de cálcio para aves leves, enquanto para aves semipesadas, o maior ganho $(15,25 \mathrm{~g})$ foi obtido com $0,769 \%$ de cálcio (Tabela 3). Estes resultados foram suficientes para afetar a conversão alimentar, sendo estas minimizadas (3,90 e 3,50) aos níveis de 0,778 e 0,815\% de cálcio, respectivamente, para aves leves e semipesadas (Tabela 3). Observa-se que a exigência de cálcio para minimizar a conversão alimentar foi superior a exigência para máximo ganho de peso, independentemente do tipo de ave.

Narváez et al. (1997) observaram que as exigências para conversão alimentar são superiores às exigências para todos os outros parâmetros produtivos, exceto para resistência óssea. Embora tenha havido efeito significativo $(\mathrm{P}<0,05)$ para ganho e conversão alimentar, nota-se que o consumo de ração não foi afetado. Com o aumento do nível de cálcio na ração, verificou-se maior consumo deste mineral, o que proporcionou efeito quadrático para ganho de peso e conversão alimentar.

Não houve diferenças significativas entre os parâmetros ósseos, mesmo quando as aves foram alimentadas com baixos níveis de cálcio na ração. Provavelmente, isto ocorreu porque, em rações deficientes, há melhor aproveitamento do cálcio, pelo aumento da eficiência de absorção intestinal (Hamilton \& Cipera, 1981). Por outro lado, com o aumento dos níveis de cálcio, houve redução do aproveitamento do cálcio pela ave, fazendo com que os parâmetros ósseos estudados não diferissem entre si (Tabela 2). 
Existem duas vias de absorção de cálcio: a saturável e a não saturável (Bronner,1987). No processo saturável há dependência das proteínas ligadoras de cálcio, cuja quantidade nas células epiteliais é pouco variável, assim, em menores quantidade do mineral, a relação cálcio: proteína ligadora é maior e, por conseguinte, há maior digestibilidade.

Salim (1981), citado por Taher et al. (1984), trabalhando com poedeiras, observou que as aves alimentadas com maior quantidade de ração, em função dos baixos níveis de cálcio na ração, de forma a ingerir quantidade adequada de cálcio para manter as funções metabólicas normais. No entanto, estes mesmos autores verificaram ainda que em rações com baixos níveis de cálcio, as aves não conseguiam consumir a quantidade adequada de ração, para atender à necessidade do mineral.

Tabela 2 - Efeitos dos níveis nutricionais de cálcio sobre o desempenho e parâmetros ósseos de aves de reposição leves (L) e semipesadas (SP) de 7 a 12 semanas de idade

Table 2 - Effects of nutritional levels of calcium on performance and bone parameters of white-egg pullets $(L)$ and brown-egg pullets (SP) replacement from 7 to 12 weeks of age

\begin{tabular}{|c|c|c|c|c|c|c|c|c|c|c|c|c|}
\hline \multirow[t]{2}{*}{$\begin{array}{l}\text { Cálcio } \\
(\%) \\
\text { Calcium }\end{array}$} & \multicolumn{2}{|c|}{$\begin{array}{c}\text { Consumo de ração } \\
\text { (g/ave/dia) } \\
\text { Feed intake } \\
\text { (g/chicken/day) }\end{array}$} & \multicolumn{2}{|c|}{$\begin{array}{c}\text { Ganho de peso } \\
\text { (g/ave/dia) } \\
\text { Weightgain } \\
\text { (g/chicken/day) }\end{array}$} & \multicolumn{2}{|c|}{$\begin{array}{l}\text { Conversão } \\
\text { alimentar } \\
\text { Feed: gain } \\
\text { ratio } \\
\end{array}$} & \multicolumn{2}{|c|}{$\begin{array}{c}\text { Resistência } \\
\text { óssea } \\
\text { (kgf/mm) } \\
\text { Bone resistance }\end{array}$} & \multicolumn{2}{|c|}{$\begin{array}{c}\text { Cinza óssea (\%) } \\
\text { Bone ash }\end{array}$} & \multicolumn{2}{|c|}{$\begin{array}{c}\text { Cálcio } \\
\text { ósseo (\%) } \\
\text { Bone calcium }\end{array}$} \\
\hline & $\mathrm{L}$ & SP & $\mathrm{L}$ & SP & $\mathrm{L}$ & SP & $\mathrm{L}$ & SP & $\mathrm{L}$ & SP & $\mathrm{L}$ & SP \\
\hline 0,60 & 48,40 & 55,34 & 12,10 & 15,00 & 4,00 & 3,69 & 9,62 & 12,60 & 44,03 & 41,54 & 22,48 & 23,20 \\
\hline 0,70 & 47,98 & 53,39 & 12,24 & 15,24 & 3,92 & 3,50 & 10,20 & 12,02 & 43,97 & 42,08 & 23,37 & 22,54 \\
\hline 0,80 & 49,85 & 53,98 & 12,64 & 15,33 & 3,94 & 3,52 & 10,32 & 13,21 & 43,06 & 44,12 & 22,30 & 23,26 \\
\hline 0,90 & 47,62 & 53,03 & 12,19 & 14,99 & 3,91 & 3,54 & 9,70 & 11,65 & 44,81 & 41,26 & 23,24 & 22,47 \\
\hline 1,00 & 49,40 & 53,82 & 12,12 & 14,88 & 4,08 & 3,62 & 10,58 & 12,23 & 43,73 & 43,49 & 22,92 & 21,16 \\
\hline $\begin{array}{l}\text { Média }^{1} \\
\text { Average }\end{array}$ & 48,65b & 53,91a & $12,26 b$ & 15,09a & $3,97 b$ & $3,57 a$ & 10,08b & $12,34 a$ & $43,92 a$ & 42,50b & 22,86 & 22,53 \\
\hline $\begin{array}{l}\text { Efeito } \\
\text { Effect }\end{array}$ & NS & NS & $\mathrm{Q}^{*}$ & $\mathrm{Q}^{*}$ & Q\# & $\mathrm{Q}^{*}$ & NS & NS & NS & NS & NS & NS \\
\hline CV(\%) & 3,300 & 2,093 & 3,424 & 7,505 & 2,898 & 8,449 & & & & & & \\
\hline
\end{tabular}

1 Médias seguidas pela mesma letra dentro de um mesmo parâmetro, não diferem entre si pelo teste $\mathrm{F}$; $\mathrm{CV}=\mathrm{coeficiente}$ de variação. $\mathrm{Q}$ - efeito quadrático; NS - efeito não-significativo; * $(\mathrm{P}<0,05)$, \#(P<0,078). Resistência óssea em kgf/ mm, em que $1 \mathrm{~N}=0,1020 \mathrm{kgf} / \mathrm{mm}$.

${ }^{1}$ Means followed by the same letter in same parameter do not differ by $F$ test; CV = coefficient of variation; $Q$ - quadratic effect; NS - not significant effect; ${ }^{*}(P<.05) ;{ }^{\#}(P<.078)$. Bone resistance in $\mathrm{kgf} / \mathrm{mm}$, in which $1 \mathrm{~N}=.1020 \mathrm{kgf} / \mathrm{mm}$.

Tabela 3 - Exigência de cálcio para aves de reposição leve (L) e semipesada (SP), considerando parâmetros de desempenho e ósseo

Table 3 - Calcium requirements for white-egg pullets $(L)$ and brown-egg pullets replacement, considering performance and bone parameters

\begin{tabular}{|c|c|c|c|c|c|c|}
\hline \multicolumn{2}{|c|}{$\begin{array}{l}\text { Parâmetro } \\
\text { Parameter }\end{array}$} & \multirow[t]{2}{*}{$\begin{array}{l}\text { Equação } \\
\text { Equations }\end{array}$} & \multirow[t]{2}{*}{$\mathrm{R}^{2}$} & \multirow[t]{2}{*}{$\mathrm{Max} / \mathrm{min}$} & \multicolumn{2}{|c|}{$\begin{array}{c}\text { Exigências } \\
\text { Requirements }\end{array}$} \\
\hline & & & & & $(\%)$ & $\begin{array}{c}\text { (\%/ Mcal EM) } \\
\text { (\%/ Mcal ME) }\end{array}$ \\
\hline$\overline{\mathrm{GP}}$ & $\mathrm{L}$ & $Y=6,6252+14,5541 x-9,1042 x^{2}$ & 0,59 & 12,43 & 0,799 & 0,276 \\
\hline$W G$ & SP & $Y=10,4843+12,4096 x-8,0668 x^{2}$ & 0,82 & 15,25 & 0,769 & 0,265 \\
\hline$\overline{\mathrm{CA}}$ & $\mathrm{L}$ & $Y=5,8088-4,8940 x+3,1461 x^{2}$ & 0,81 & 3,90 & 0,778 & 0,268 \\
\hline$F G$ & SP & $Y=6,0117-6,1715 x+3,7874 x^{2}$ & 0,88 & 3,50 & 0,815 & 0,281 \\
\hline
\end{tabular}

GP - ganho de peso (g/ave/dia); CA - conversão alimentar (g: g).

WG - weight gain (g/chicken/day); FG - feed: gain ratio (g: $g)$.

R. Bras. Zootec., v.33, n.4, p.936-946, 2004 
Em aves adultas, dietas deficientes em cálcio causam maior mobilização óssea, e os ossos tornam-se porosos, tornando-os menos resistentes à quebra. Em frangas, isto não é totalmente verdadeiro, a não ser que haja grande deficiência, pois as aves possuem demanda de cálcio quase que exclusivamente para formação óssea (Scott et al., 1982), uma vez que cerca de $90 \%$ do tamanho corporal da franga é atingido por volta da $12^{\underline{a}}$ a $16^{\underline{a}}$ semanas de idade (Leeson \& Summers, 1997). De acordo com Zollitsch et al. (1996), a mobilização óssea de cálcio ou de fósforo somente comprometerá a resistência, em casos de deficiência prolongada. Keshavarz (1986) observou que aves jovens são menos susceptíveis aos efeitos de altos níveis de cálcio que aves mais velhas. Leeson et al. (1986) constataram que o aumento de cálcio em aves imaturas resulta maior retenção de cálcio, que seria utilizado para a mineralização óssea por meio da mineralização da medula.

Fase de produção de ovos

Observou-se, para aves leves que o consumo de ração, a produção de ovos, o peso médio dos ovos e a conversão alimentar (g/g e kg/dz), não foram afetados de forma significativa $(\mathrm{P}>0,05)$ pelos níveis de cálcio utilizados na fase de crescimento (Tabela 4). Por outro lado, a massa de ovo foi afetada de forma significativa $(\mathrm{P}<0,05)$ aumentando até o nível de $0,834 \%$ de cálcio, fazendo com que as aves tivessem produção máxima de 43,85 g de ovo/ave/dia (Tabela 5).

As aves semipesadas não apresentaram diferenças significativas no peso médio dos ovos e na massa de ovo (Tabela 4), porém houve máximo consumo de ração (107,53 g) no nível de 0,782\% de cálcio, máxima produção de ovos (86,35\%), com 0,783\% e melhor conversão alimentar (2,19 g/g e 1,50 kg ração/dúzia ovo), com 0,767 e 0,783\% de cálcio (Tabela 5).

Ao comparar os parâmetros produtivos das aves leves e das aves semipesadas, verificou-se que, na média, as aves semipesadas apresentaram consumo de ração, peso médio dos ovos, massa de ovos e conversão alimentar $(\mathrm{kg} / \mathrm{dz})$ maiores que aves leves pelo teste $\mathrm{F}(\mathrm{P}<0,05)$, enquanto a produção de ovos e a conversão alimentar (g/g) não diferiram entre os tipos de aves.

Exigências nutricionais de fósforo disponível

Fase de crescimento

Os resultados dos diferentes níveis de fósforo disponível nas rações sobre o desempenho e características ósseas de aves de reposição leves e

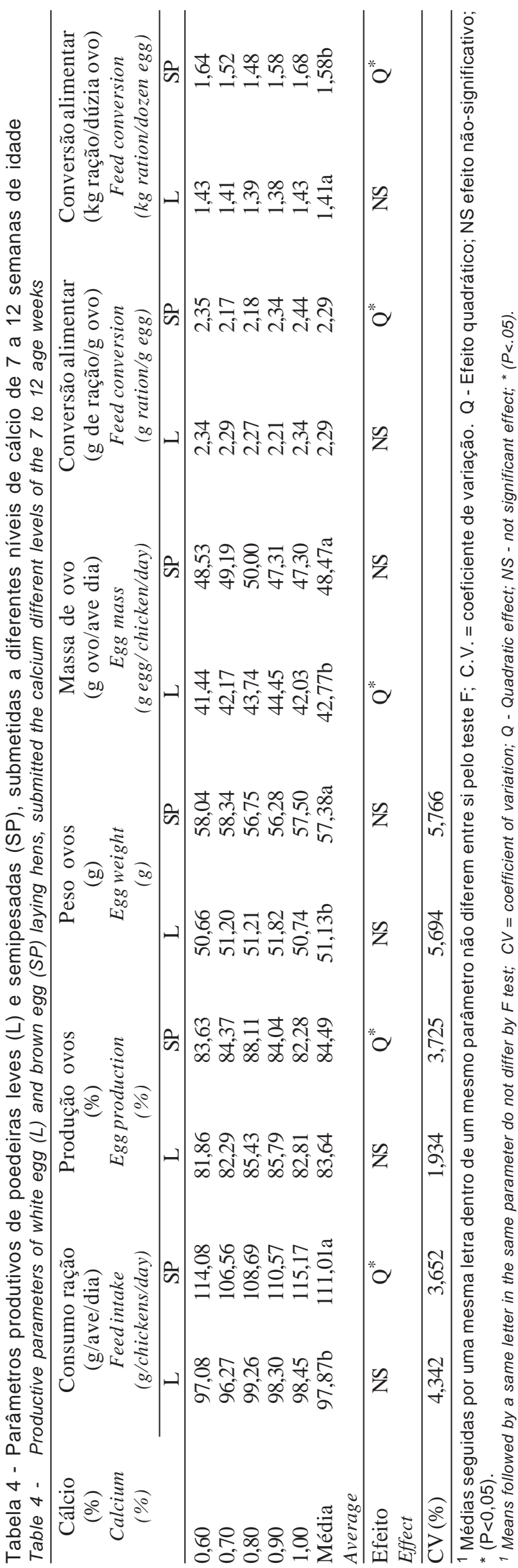

R. Bras. Zootec., v.33, n.4, p.936-946, 2004 
semipesadas são apresentados na Tabela 6. Observou-se efeito não significativo para conversão alimentar, resistência óssea e cinza óssea de aves leves, e para consumo de ração, conversão alimentar e cinza óssea de aves semipesadas.

Para aves leves, o máximo consumo de ração (49,34 g), obtido ao nível de 0,366\% de fósforo disponível (Tabela 7), não foi suficiente para influenciar a conversão alimentar. No entanto, esse consumo fez com que o ganho de peso fosse afetado de forma significativa, pois houve máximo ganho $(12,48 \mathrm{~g})$ com 0,373\% de fósforo disponível na ração. Ao mesmo tempo, em termos percentuais, a exigência para máximo consumo não foi suficiente para obter maior ganho, o que pode ser comprovado pelo nível de cálcio na ração necessário para cada parâmetro. Com o consumo de 49,34 g, a ave ingeriu $181 \mathrm{mg}$ de cálcio, enquanto para o maior ganho de peso necessitou consumir 49,29 g de ração, originando ingestão de $184 \mathrm{mg}$ de cálcio (Tabela 6). Apesar de as diferenças na quantidade de cálcio ingerida serem pequenas, observou-se que, em termos percentuais, foram maiores, comprovando que a ave ajusta o consumo de cálcio de acordo com sua necessidade. Ao mesmo tempo, as exigências de aves de reposição também deveriam ser expressas em gramas ou miligramas por ave por dia.

O ganho de peso de aves semipesadas foi afetado de forma significativa $(\mathrm{P}<0,05)$ pelos níveis de fósforo na ração. Pode-se observar que houve aumento do ganho até o nível de $0,354 \%$ de fósforo, o que correspondeu a ganho de 14,58 g/ave/dia (Tabela 7). Embora o ganho de peso tenha sido influenciado pelos níveis de fósforo, estes não foram suficientes para afetar a conversão alimentar. Brugalli et al. (1999), trabalhando com frangos de corte na fase de crescimento, observaram que as diferenças no ganho de peso foram suficientes para afetar a conversão alimentar.

Por meio dos resultados encontrados para parâmetros ósseos, pode-se observar que os níveis de fósforo estudados não afetaram de forma significativa a resistência e cinza óssea para aves leves, e cinza óssea para aves semipesadas. Nelson et al. (1990) encontraram aumento da cinza óssea com o aumento do nível de fósforo na ração. No entanto, foi encontrada para aves semipesadas maior resistência óssea com o nível de 0,361\% de fósforo disponível (Tabela 7), originando resistência óssea máxima de 13,53 kgf/ mm, enquanto nível máximo fósforo ósseo $(13,17 \%)$ foi obtido com $0,329 \%$. As aves leves maximizaram (13,27\%) o fósforo ósseo com $0,338 \%$. Estes resultados discordam de observações feitas por Rostagno et al. (1996) e Brugalli et al. (1999), de que a exigência nutricional para otimizar desempenho das aves é inferior às exigências para maximizar resistência óssea, ao mesmo tempo em que Wilson \& Duff (1991), citados por Rennie et al. (1997), observaram que, em aves alimentadas com rações deficientes em cálcio ou fósforo, há perda de material ósseo. De acordo com Zollitsch et al. (1996), a mobilização óssea para atender às necessidades

Tabela 5 - Exigência de cálcio para aves de reposição leves (L) e semipesadas (SP), considerando parâmetros de desempenho (fase de produção) e ósseo

Table 5 - Calcium requirements for white-egg pullets $(L)$ and brown-egg pullets replacement, considering performance (egg production phase) and bone parameters

\begin{tabular}{|c|c|c|c|c|c|c|}
\hline \multirow{2}{*}{\multicolumn{2}{|c|}{$\begin{array}{l}\text { Parâmetro } \\
\text { Parameter }\end{array}$}} & \multirow[t]{2}{*}{$\begin{array}{l}\text { Equação } \\
\text { Equation }\end{array}$} & \multirow[t]{2}{*}{$\mathrm{R}^{2}$} & \multirow[t]{2}{*}{ Max/min } & \multicolumn{2}{|c|}{$\begin{array}{l}\text { Exigências } \\
\text { Requirements }\end{array}$} \\
\hline & & & & & (\%) & $\begin{array}{c}\text { (\%/ Mcal EM) } \\
(\% / \text { Mcal ME) }\end{array}$ \\
\hline$\overline{\mathrm{CRp}}$ & FI SP & $Y=212,3130-268,0160 x+171,3850 x^{2}$ & 0,86 & 107,53 & 0,782 & 0,270 \\
\hline & EP SP & $Y=30,1205+143,5390 x-91,6126 x^{2}$ & 0,67 & 86,35 & 0,783 & 0,270 \\
\hline MO & $E M \quad \mathrm{~L}$ & $Y=8,2512+85,3655 x-51,1775 x^{2}$ & 0,75 & 43,85 & 0,834 & 0,288 \\
\hline CAg & $F G g$ SP & $Y=5,2058-7,8755 x+5,1339 x^{2}$ & 0,87 & 2,19 & 0,767 & 0,265 \\
\hline CAdz & $F G d z$ SP & $Y=4,0150-6,4363 x+4,1110 x^{2}$ & 0,96 & 1,50 & 0,783 & 0,270 \\
\hline
\end{tabular}

CRp - consumo de ração fase de produção (g/ave/dia); PO - produção de ovos (\%); MO - massa de ovo (g de ovo/ave/ dia); CAg - conversão alimentar fase produção (g ração: g ovo/ave/dia); CAdz - conversão alimentar fase de produção (kg ração: dúzia de ovo).

Flp - feed intake production phase; EP - egg production (\%); EM - egg mass ( $g$ of egg/chickens/day); BO - bone resistance (kgf/ $\mathrm{mm})$; Ca bone - calcium in bone.

\section{R. Bras. Zootec., v.33, n.4, p.936-946, 2004}



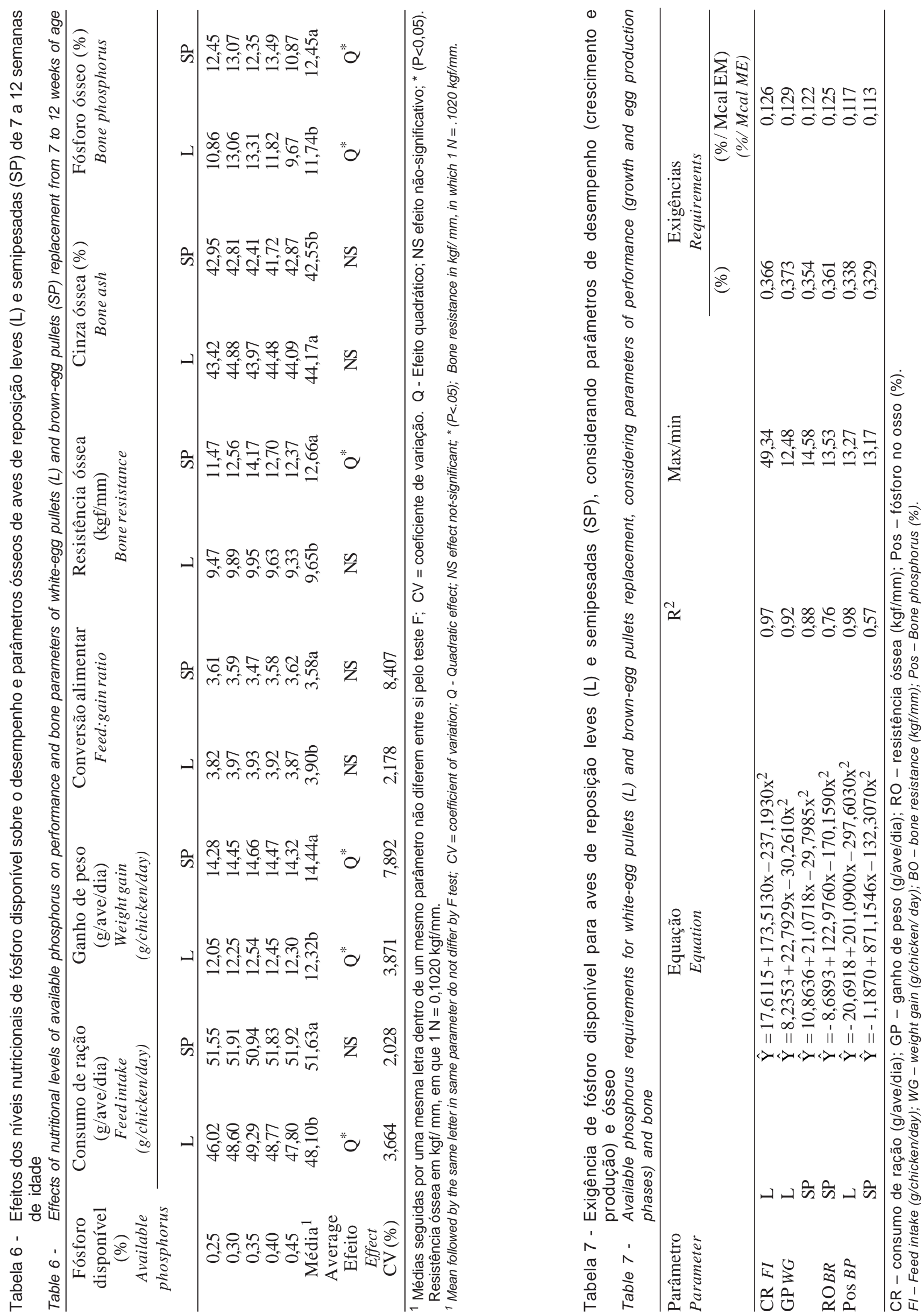

\section{R. Bras. Zootec., v.33, n.4, p.936-946, 2004}


metabólicas é processo normal e a perda óssea somente comprometerá a resistência, quando houver deficiência prolongada. Huyghebaert \& DeGroote (1988) observaram que nem sempre a porcentagem de cinza óssea está relacionada à resistência à quebra.

A comparação entre aves leves e semipesadas, dos diversos parâmetros estudados, mostrou que, na média, o consumo de ração, o ganho de peso e a resistência óssea e fósforo no osso das aves semipesadas foram superiores aos das aves leves, enquanto conversão alimentar e cinza óssea das aves leves foram maiores. Estes resultados demonstraram que, independentemente do nível de fósforo disponível, as aves semipesadas apresentaram maior desenvolvimento corporal que as leves.

\section{Fase de produção de ovos}

Os resultados dos níveis de fósforo disponível, na fase de recria, sobre os parâmetros produtivos, na fase de produção de ovos, podem ser encontrados na Tabela 8. Observa-se que consumo de ração, produção de ovos, peso dos ovos, massa de ovo e conversão alimentar (kg de ração/dúzia de ovo) das aves semipesadas foram significativamente maiores que das aves leves.

Consumo de ração e peso médio dos ovos de aves leves ou semipesadas, e conversão alimentar (kg/dz) de aves semipesadas, não foram afetados de forma significativa pelos níveis de fósforo da fase de recria. No entanto, verificou-se que a produção de ovos foi maximizada (82,67 e 83,01\%) no nível de 0,407 e 0,350\% de fósforo disponível, respectivamente, para aves leves e semipesadas (Tabela 9).

Apesar de o peso médio dos ovos não ter apresentado diferenças entre os tratamentos, a massa de ovo foi afetada de forma significativa $(\mathrm{P}<0,05)$, provavelmente em razão das diferenças observadas para produção de ovos, uma vez que a massa de ovo é a relação entre a produção e o peso médio. Para aves leves, a maior massa de ovo (43,03 g/ave/dia) foi encontrada com $0,411 \%$, enquanto para aves semipesadas esta maior massa de ovo (47,66 g/ave/dia) foi obtida com $0,348 \%$ de fósforo disponível na ração.

Verificou-se que as aves leves tiveram máxima conversão alimentar $(3,86)$ no nível de $0,407 \%$ e as semipesadas $(3,87)$, com $0,350 \%$ de fósforo disponível. No entanto, a análise do consumo de ração pelo número de dúzia de ovos produzidos apresentou efeito somente para as aves leves, sendo que, à medida aumentou o nível de fósforo da ração, houve redução da conversão alimentar.

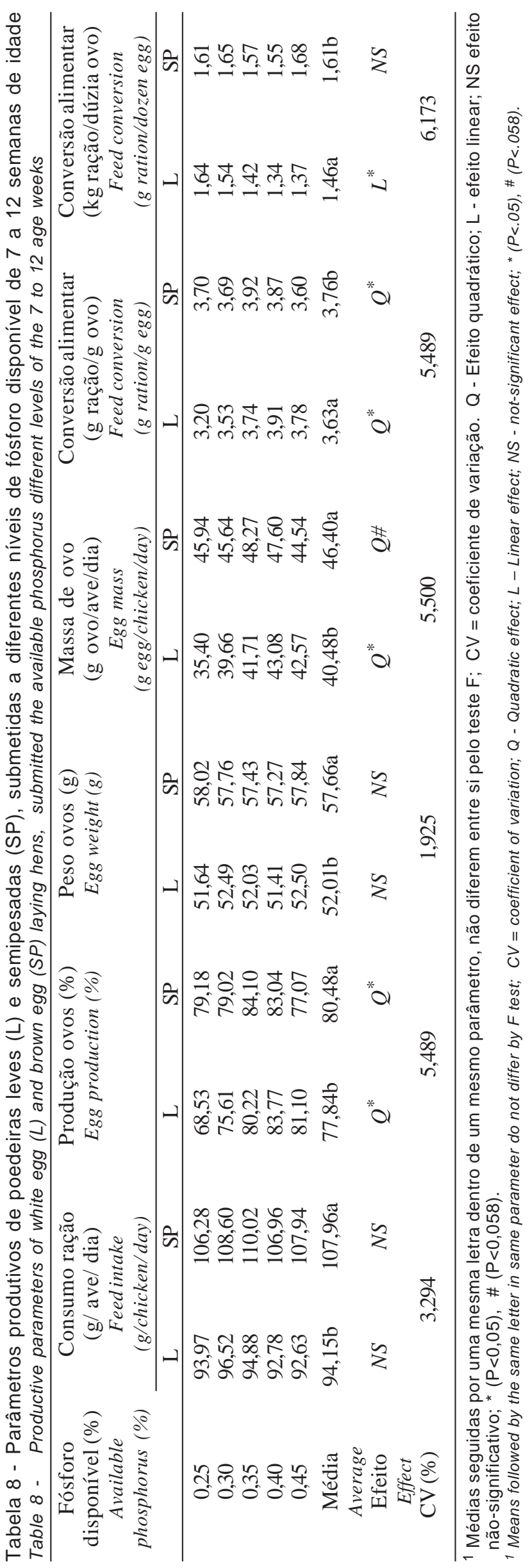

\section{R. Bras. Zootec., v.33, n.4, p.936-946, 2004}


Tabela 9 - Exigência de fósforo disponível para aves de reposição leves (L) e semipesadas (SP), considerando parâmetros de desempenho (fase de produção) e ósseo

Table 9 - Available phosphorus requirements for white-egg pullets $(L)$ and brown-egg pullets replacement, considering performance (egg production phases) and bone parameters

\begin{tabular}{|c|c|c|c|c|c|c|}
\hline \multirow[t]{2}{*}{$\begin{array}{l}\text { Parâmetro } \\
\text { Parameter }\end{array}$} & & \multirow[t]{2}{*}{$\begin{array}{l}\text { Equação } \\
\text { Equation }\end{array}$} & \multirow[t]{2}{*}{$\mathrm{R}^{2}$} & \multirow[t]{2}{*}{ Max/min } & \multicolumn{2}{|c|}{$\begin{array}{l}\text { Exigências } \\
\text { Requirements }\end{array}$} \\
\hline & & & & & $(\%)$ & $\begin{array}{r}(\% / \text { Mcal EM) } \\
(\% / \text { Mcal ME) }\end{array}$ \\
\hline \multirow[t]{2}{*}{ POEP } & $\mathrm{L}$ & $\hat{Y}=-14,5437+478,1540 x-587,9630 x^{2}$ & 0,99 & 82,67 & 0,407 & 0,140 \\
\hline & $\mathrm{SP}$ & $\hat{Y}=21,0905+354,2800 x-506,7270 x^{2}$ & 0,64 & 83,01 & 0,350 & 0,121 \\
\hline \multirow[t]{2}{*}{ MO EM } & $\mathrm{L}$ & $\hat{Y}=-6,2823+240,0410 x-292,1400 x^{2}$ & 0,99 & 43,03 & 0,411 & 0,142 \\
\hline & SP & $\hat{\hat{Y}}=17,3853+174,6220 x-251,8060 x^{2}$ & 0,61 & 47,66 & 0,348 & 0,120 \\
\hline \multirow{2}{*}{ CAg FCg } & $\mathrm{L}$ & $\hat{Y}=-0,6787+22,3139 x-27,4383 x^{2}$ & 0,99 & 3,86 & 0,407 & 0,140 \\
\hline & $\mathrm{SP}$ & $\hat{\hat{Y}}=0,9842+16,5331 x-23,6473 x^{2}$ & 0,64 & 3,87 & 0,350 & 0,121 \\
\hline CAd FCd & $\mathrm{L}$ & $\hat{\mathrm{Y}}=1,9837-1,6145 \mathrm{x}$ & 0,86 & - & $\geq 0,45$ & - \\
\hline
\end{tabular}

PO - produção de ovos (\%); MO - massa de ovo (g de ovo/ave/ dia); CAg - conversão alimentar fase produção (g ração:g ovo/ave/ dia); CAd - conversão alimentar na fase de produção ( $\mathrm{kg}$ ração:dúzia de ovo).

EP - egg production (\%); EM - egg mass (g egg/chicken/day); FCg - Feed conversion production phase (g ration/g egg); FCd - Feed conversion production phase ( $k g$ ration/ dozen eggs).

\section{Conclusões}

As exigências nutricionais de cálcio para aves leves e semipesadas no período de 7 a 12 semanas de idade foram estimadas em, respectivamente, $0,834 \%$ (0,288\%/Mcal de EM) ou $406 \mathrm{mg} /$ ave/dia e 0,815\% $(0,281 \% /$ Mcal de EM) ou $440 \mathrm{mg} /$ ave/dia e as exigências nutricionais de fósforo disponível em $0,411 \%$ $(0,142 \% /$ Mcal de EM) ou $200 \mathrm{mg} /$ ave/dia e $0,361 \%$ (0,125\%/Mcal de EM) ou $184 \mathrm{mg} /$ ave/dia, respectivamente, para aves leves e semipesadas.

\section{Literatura Citada}

BRONNER, F. Intestinal Calcium Absorption: Mechanisms and Applications. Journal Nutrition, v.117, p.1347-1352, 1987.

BRUGALLI, I.; SILVA, D.J.; ALBINO, L.F.T. et al. Exigência de fósforo disponível e efeito da granulometria na biodisponibilidade de fósforo da farinha de carne e ossos para pintos de corte. Revista Brasileira de Zootecnia, v.28, n.6, p.1288-1296, 1999.

HAMILTON, R.M.G.; CIPERA, J.D. Effects dietary calcium levels during the brooding, rearing, and early laying period on feed intake, egg production, and shell quality of white leghorn hens. Poultry Science, v.60, n.2, p.349-357, 1981.

HUYGHEBAERT, G., DeGROOTE, G. Effect of dietary fluoride on performance and bone characteristics of broiler and the influence of dryng and deffating on bone breaking strength. Poultry Science, v.67, n.6, p.950-955, 1988.

KESHAVARZ, K. Influence of feeding a high calcium diet for various durations in prelaying period on growth and subsequent performance off white leghorn pullets. Poultry Science, v.66, n.10, p.1576-1582, 1987.

KESHAVARZ, K. The effect of dietary levels of calcium and phosphorus on performance and retention of these nutrients by laying hens. Poultry Science, v.65, n.1, p.114-121, 1986

KESHAVARZ, K.; NAKAJIMA, S. Re-evaluation of calcium and phosphorus requirements of laying hens for optimum performance and eggshell quality. Poultry Science, v.72, n.1, p.144-153, 1993.

LEESON, S.; JULIAN, R.J.; SUMMERS, J.D. Influence of prelay and early-lay dietary calcium concentration on performance and bone integrity of leghorn pullets. Canadian Journal Animal Science, v.66, n.4, p.1087-1095, 1986.

LEESON, S.; SUMMERS, J.D. Commercial poultry nutrition. 2.ed. Guelph-Ontário: Univerty Books, 1997. 355p.

MORAN JR., E.T. Egg quality and hen performance responses to protein-calcium deficiency, cafeteria feeding, and cage density, Poultry Science, v.65, n.6, p.1153-1162, 1986.

NARVÁEZ, W.V.; ROSTAGNO, H.S.; SOARES, P.R. et al. Níveis de cálcio para poedeiras comerciais leves de 46 a 62 semanas de idade. In: REUNIÃO ANUAL DA SOCIEDADE BRASILEIRA DE ZOOTECNIA, 34., 1997, Juiz de Fora. Anais... Juiz de Fora: Sociedade Brasileira de Zootecnia, 1997. p.27.

NATIONAL RESEARCH COUNCIL - NRC. Nutrient requirements of poultry. 9.rev.ed. Washington, DC.: 1994. 155p.

NELSON, T.S.; HARRIS, G.C.; KIRBY, L.K. et al. Effect of calcium and phosphorus on the incidence of leg abnormalities in growing broilers. Poultry Science, v.69, n.10, p.14961502, 1990

RENNIE, J.S.; FLEMING, R.H.; McCORMACK, H.A. et al. Studies on effects of nutritional factors on bone structure and osteoporosis in laying hens. British Poultry Science, v.38, n.4, p.417-424, 1997.

ROSTAGNO, H.S.; BARBARINO JR., P.; BARBOZA, W.A. Exigências nutricionais de aves determinadas no Brasil. In: SIMPÓSIO INTERNACIONAL SOBRE EXIGÊNCIAS NUTRICIONAIS DE AVES E SUÍNOS, 1996, Viçosa MG, Anais ... Viçosa, MG: Universidade Federal de Viçosa, 1996. p.361-388.

R. Bras. Zootec., v.33, n.4, p.936-946, 2004 
ROSTAGNO, H.S.; SILVA, D.J.; COSTA, P.M.A. et al. Composição de alimentos e exigências nutricionais de aves e suínos (Tabelas brasileiras). Viçosa - MG: Universidade Federal de Viçosa, 1994. 61p.

SCOTT, M.L.; NESHEIM, M.C.; YOUNG, R.J. Essential inorganic elements - Nutrition of the chicken. 3.ed. New York: M.L Scott Associates, 1982. p.287-304.

SHAFEY, T.M.; McDONALD, M.W.; PIM, R.A.E. The effect of dietary calcium upon growth rate, food utilisation and plasma constituents in lines of chickens selected for aspects of growth or body composition. British Poultry Science, v.31, n.6, p.577-586, 1990.

SILVA, D.J. Análises de alimentos (métodos químicos e biológicos). Viçosa, MG: Universidade Federal de Viçosa, 1990. 165p.

TAHER, A.I.; GLEAVES, E.W.; BECK, M. Special calcium appetite in laying hens. Poultry Science, v.63, n.11, p.2261-2267, 1984.
UNIVERSIDADE FEDERAL DE VIÇOSA - UFV. SAEG Sistema de Análises Estatísticas e Genéticas. Versão 7.1. Viçosa, MG: 1997. 59p. (Manual do Usuário).

ZOOLLITSCH, W.; ZHIQIANG, C.; PEGURI, A. et al. Nutrient requirements of laying hens. In: SIMPÓSIO INTERNACIONAL SOBRE EXIGÊNCIAS NUTRICIONAIS DE AVES E SUÍNOS, 1996, Viçosa, MG. Anais... Viçosa, MG: Universidade Federal de Viçosa, 1996. p.109-159.

Recebido em: 15/10/02

Aceito em: 06/05/03 